Journal of Advanced Research in Fluid Mechanics and Thermal Sciences

Journal homepage: www.akademiabaru.com/arfmts.html ISSN: $2289-7879$

\title{
Study on the Performance Analysis of Dual Fuel Engines on the Medium Speed Diesel Engine
}

\author{
Muhammad Arif Budiyanto ${ }^{1,}{ }^{*}$, Agus Sunjarianto Pamitran ${ }^{1}$, Hadi Tresno Wibowo ${ }^{1}$, Fahd Naufal \\ Murtado ${ }^{1}$
}

1 Department of Mechanical Engineering, Universitas Indonesia, Kampus Baru UI Depok, Jawa Barat, 16424 Indonesia

\section{ARTICLE INFO ABSTRACT}

\section{Article history:}

Received 16 December 2019

Received in revised form 27 January 2020

Accepted 1 February 2020

Available online 25 March 2020

Keywords:

Dual-fuel engine; gas mixture; passenger ship

\begin{abstract}
This paper aims to analyze the performance of the dual-fuel diesel engine effect of variation of the gas mixture. Medium-speed diesel engines from the passenger ship 3200 DWT has been chosen a case study in consideration for the dual-fuel engine conversion. The analysis was performed based on the result of the simulation model by computational fluid dynamics. Mean effective pressure (MEP) as engine performance indicator has obtained from the simulation, thus the power and thermal efficiency calculated using empirical equations. Five variations of a gas mixture are determined i.e. $30 \%, 40 \%, 50 \%, 60 \%, 70 \%$ to obtain performance changes. The results of the analysis show different performance characteristics on the increase of gas mixtures. The optimum performance of the dual-fuel engine was obtained at a $60 \%$ gas mixture where achieved its maximum power and thermal efficiency.
\end{abstract}

Copyright @ 2020 PENERBIT AKADEMIA BARU - All rights reserved

\section{Introduction}

Nowadays, marine diesel oil is widely used as major fuel in marine diesel engines for ship propulsion [1,2]. According to the Indonesian Central Bureau of Statistics, ship calls of port in Indonesia in 2017 reached 842,08 thousand unit or increased by 6,73 percent in 2017 [3]. This resulted in the need for fossil fuels in Indonesia will continue to increase and inversely proportional to the declining availability of fossil fuels. The use of gas fuel in modern transportation has been introduced in the world for a long time [4]. The use of natural gas as fuel is the main solution to reduce fossil fuel consumption due to the declining number of fossil fuels but increased gas fuel production from 1800 BCM (Billion Cubic Meter) to 2500 BCM in the Asia Pacific within 10 years and also consumption is increasing in the last 10 years [5].

The Ministry Transportation of Republic Indonesia (MTRI) aims to regulate national shipping that provides sea transportation services, including passenger transport services, and inter-island cargo.

\footnotetext{
* Corresponding author.

E-mail address: arif@eng.ui.ac.id (Muhammad Arif Budiyanto)
} 
Currently, the company under the MTRI operates approximately 26 passenger ships, 46 pioneer ships, 6 sea freighter ships, and 1 livestock vessel [6]. The fuel used in all of the company's vessels is diesel oil with single fuel main engines i.e. engines that use one type of fuel. The use of main engine vessels that use dual fuel engines is one solution to reduce the use of fossil fuels $[7,8]$. Without having to change the main engine, single fuel engine conversion into dual fuel can be done with retrofit in the form of spark plug installation and gas injection on a used diesel engine [9-11]. Developing the dual-fuel engine has been extensively studied by several researchers to obtain optimal performance. Dual-fuel engine is the diesel engine that can run on both gaseous and liquid fuels by modified its fuel injectors. The development of the diesel engine has studied the effect of swirl using computational fluid dynamics (CFD) [12], another application of CFD using fluid motion was to investigate of the diesel engines reactor [13]. The interesting topic related to the environment is the reduction emission of diesel engine from low-grade diesel fuel [14]. In the recent development implementation of a dual-fuel engine is a strategy to improve the thermal efficiencies of internal combustion engines while simultaneously reducing their emissions [15].

Based on the recent studies of development dual-fuel technologies, research on the dual-fuel conversion from the passenger ship by application CFD is very limited. Looking at the importance of the performance of dual-fuel conversion, this paper aims to analyze the effect of gas mixture variation on the engine performance of dual-fuel diesel engine conversion. The performance analysis using data specifications from the main engine of passenger vessel 3200 DWT. This vessel is owned by MRTI in order in the planning of diesel dual-fuel conversion for the national programs.

\section{Basic Theory}

\subsection{Dual-fuel Diesel Engine}

The dual-fuel diesel engine is a diesel engine fueled by gas in the intake manifold or directly into the combustion chamber and ignition is done by a spray of diesel oil $[16,17]$. The addition of fuel to the combustion chamber to reduce the function of diesel in the combustion process. Apart from reducing the use of diesel fuel, folding fuel gas and reducing the negative emissions resulting from combustion. When the dual fuel diesel engine works in gas mode, it works by loading air and gas and also a bit of diesel fuel into the combustion chamber. At the time this engine works in diesel mode, diesel fuel alone is sprayed into the combustion chamber.

The development of a dual-fuel diesel engine was started there in 1987 by Wartsila with the first concept of gas diesel engine, and the first dual-fuel engine was introduced in 1995 [18]. The selection of the insulation type of ISO-tanks for the boiled of gas is important issues in the use of dual fuel engine conversion [19]. Dual fuel engine technology can be used as fuel and also diesel at the same time and also in rotation mode on this machine, which can be done without loss of power or speed on the machine [20]. One device used on this machine is a diesel pilot that aims to spray a little diesel on the surface of the room with the aim that it can occur in the compression process. The goal is that spraying diesel is not done in gas mode, incomplete combustion in the combustion chamber.

In Figure 1, the shift on dual diesel engine fuel engines in the same game as the diesel engine in general. However, in the intake phase, not only air enters the combustion chamber in this phase, natural gas has entered the combustion chamber. 


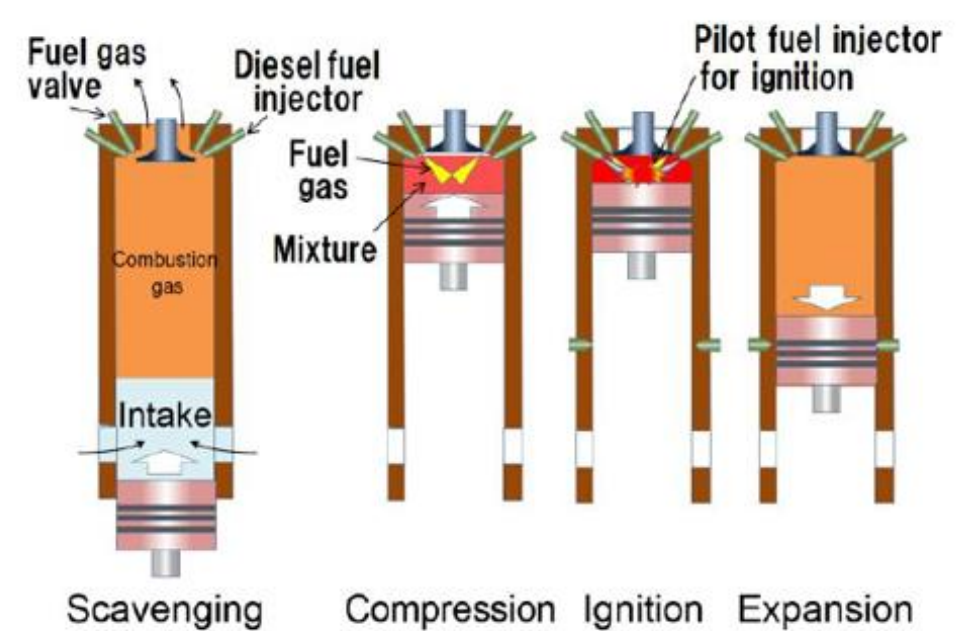

Fig. 1. Step work dual-fuel diesel engine [21]

\subsection{Cylinder Profile Movement}

Volume change on the cylinder based on rake angle change is a parameter required to know the cylinder pressure at the time of compression of the fuel to know the pressure on the cylinder. Changes in cylinder volume based on rake angle can be formulated in Eq. (1) [22]

$v(\varphi)=V \min +\frac{V \text { piston }}{2 \cdot r} \cdot\left[r \cdot(1-\cos \varphi)+l \cdot\left(1-\sqrt{1-\left(\frac{r}{l}\right)^{2} \cdot \sin ^{2} \varphi}\right)\right]$

where Vmin is the cylinder clearance volume and $v$ cylinder is the cylinder volume, $\varphi$ is the angle of the crank angle, and $/$ is the length of the connecting rod. To know the magnitude of the pressure that occurs in the cylinder based on each cylinder position when the incidence of combustion, obtained from Eq. (2) [23]

$p=p 0 \times \operatorname{Cr}^{\gamma}$

where $\mathrm{p}$ is the pressure in the cylinder prior to the combustion, the $\mathrm{Cr}$ value is a large value of the compression ratio and also $\boldsymbol{v}$ is the value of the specific ratio of heat fluid. The amount of pressure that occurs on the cylinder after the fuel has been compressed is influenced by motor pressure characteristics, volume change, and also the type of fuel.

\subsection{Engine Performance}

One important parameter of the reciprocating engine is the mean effective pressure (MEP) value which means that the pressure acting on the cylinder will produce the same work nett value at the actual cycle. The value of MEP can be formulated with Eq. (3):

$M E P=\frac{\text { Wnet }}{\text { Vpiston }}$

The Specific Fuel Consumption (SFC) is the amount of fuel consumed in units of time to convert into a large power (kw) on the machine [24]. The Specific Fuel Consumption can be written in Eq. (6) 
$S F C=\frac{\dot{\mathrm{m}}(\mathrm{a})+\dot{\mathrm{m}}(\mathrm{b})}{\text { Power }}$

where the values of $a$ and $b$ represent two different types of fuels used in the primary machine. In thermodynamics, thermal efficiency is a dimensionless measure that shows the performance of thermal equipment such as internal combustion engines and so on. The incoming heat is energy derived from energy sources. The desired output can be either heat or work, or maybe both. Thus, the thermal efficiency can be formulated by Eq. (7)

$\eta$ th $=\frac{\text { Power } x 100 \%}{[\dot{m}(a) \text { Fuel Heating Value(a) }]+[\dot{m}(\mathrm{~b}) \text { Fuel Heating Value(b) }]}$

\section{Research Methods}

\subsection{Engine Specification}

The work of this paper will require some data before then the data can be processed and analyzed, with the main data provided by the MTRI in the form of related vessel data which became the review of thesis work and also fuel consumption on the vessel during sailing. The vessel to be analyzed is an Inter-Island Sailing Ship owned by the Ministry of Transportation, which is a 3200 DWT passenger vessel with the specification in Table 1 and engine data in Table 2.

Table 1

Ship particular dimension

\begin{tabular}{ll}
\hline Length overall (LoA) & $: 146.5$ meter \\
Length between perpendicular (Lbp) & $: 130$ meter \\
Beam (B) & $: 23.4$ meter \\
Draught (T) & $: 5.9$ meter \\
Draught Minimum (Tmin) & $: 4.35$ meter \\
Dead Weight Ton (DWT) & $: 3200$ ton \\
Service Speed (Vs) & $: 17.6$ knots \\
\hline
\end{tabular}

Table 2

Engine specification

\begin{tabular}{ll}
\hline Main Engine & Krupp-MaK 6M601C \\
\hline Type & $6400 \mathrm{~kW} / 428 \mathrm{rpm}$ \\
Power & $430 \mathrm{~mm}$ \\
Bore & $610 \mathrm{~mm}$ \\
Stroke & $177 \mathrm{~g} / \mathrm{kWh}$ \\
Specific fuel consumption &
\end{tabular}

\subsection{Simulation Process}

The simulation model was performed by computational fluid dynamics (CFD) using ANSYS FLUENT. This software can model 3-dimensional flow, and also in completing the simulation of the combustion process in the cylinder chamber, this software can be used because it can provide accurate results [25]. CFD is a fundamental, powerful technique to lead ultimately to better engineering design, be that of an aircraft wing, turbomachinery blade [26]. A CFD simulation by ANSYS FLUENT able to predict the heat transfer coefficient and Nusselt number for forced convection heat transfer of water Nano fluids [27]. To do the modelling on this software, there are several steps that must be done in the form of create geometry and mesh on the model, checking the mesh model, 
choosing the right formulation, select the basic equations to be used and analysed, determine the type of material on the model, determine the boundary condition, iterates $[28,29]$. Modelling is important in using ANSYS software. In doing the modelling, the objects depicted in this software must have the same geometry with the original object. This results in prior to the drawing, it is necessary to review the data to reduce the form of errors that can occur later.

In Figure 2 it is a modelling using Design Modeller that has one package in the fluent. In this case, the component to be analyzed is a diesel cylinder because it is related to combustion in a diesel engine. Therefore, the depiction is done in three-dimensional form with the geometry resembling the original.

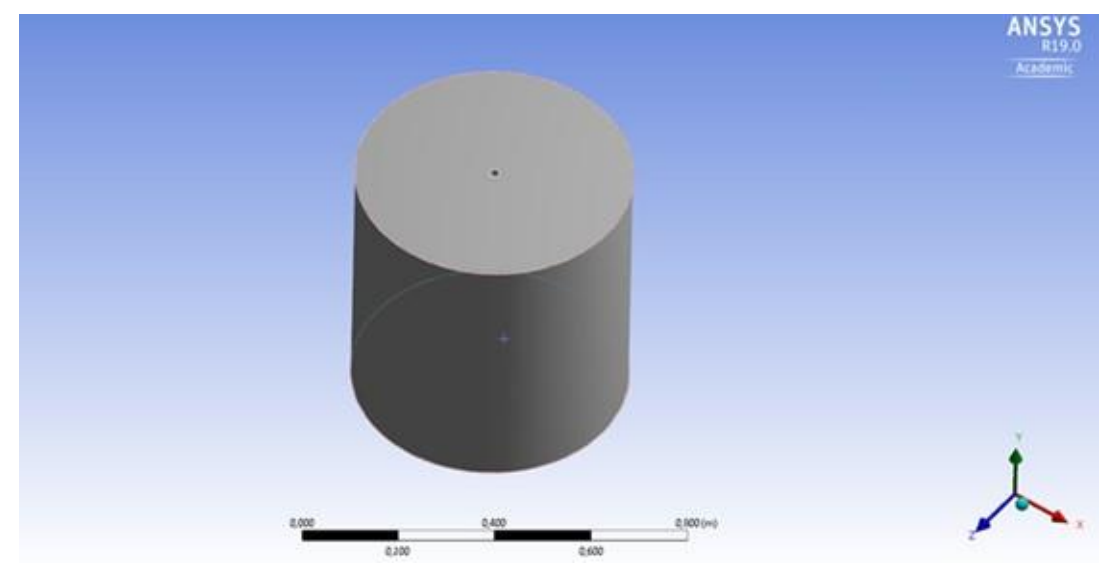

Fig. 2. Cylinder model

\subsection{Meshing and Set Up}

Performing meshing on a model object aims to model divided into small parts in order to influence the accuracy of CFD analysis. The smaller the object is divided, then the accuracy of the analysis on this software will be more accurate [30,31]. In Figure 3 we can see the model already in mesh.

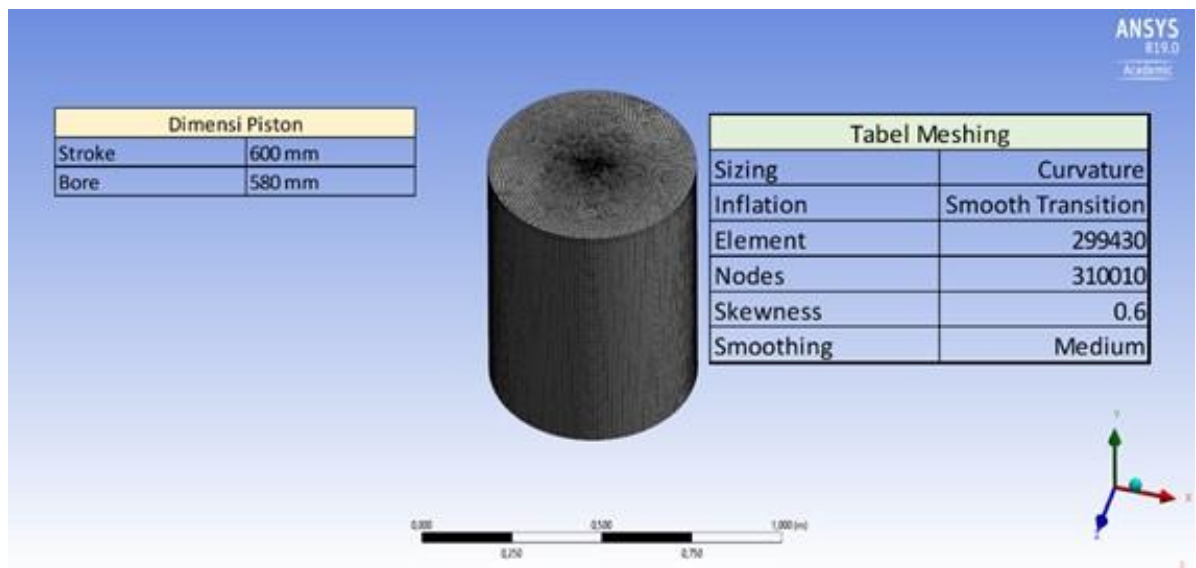

Fig. 3. Mesh set-up of cylinder model

Before performing simulations on ANSYS software, setup on this software is essential for simulation to work on the conditions we want. In this process, we determine any formulation which is influential during the simulation process that runs in Figure 4. Changes in cylinder volume, type of fuel used, and pressure changes are formulations included in this process. Eq. (1) and (2) are 
parameters included in this process with the aim of limiting the movement occurring in later simulations.

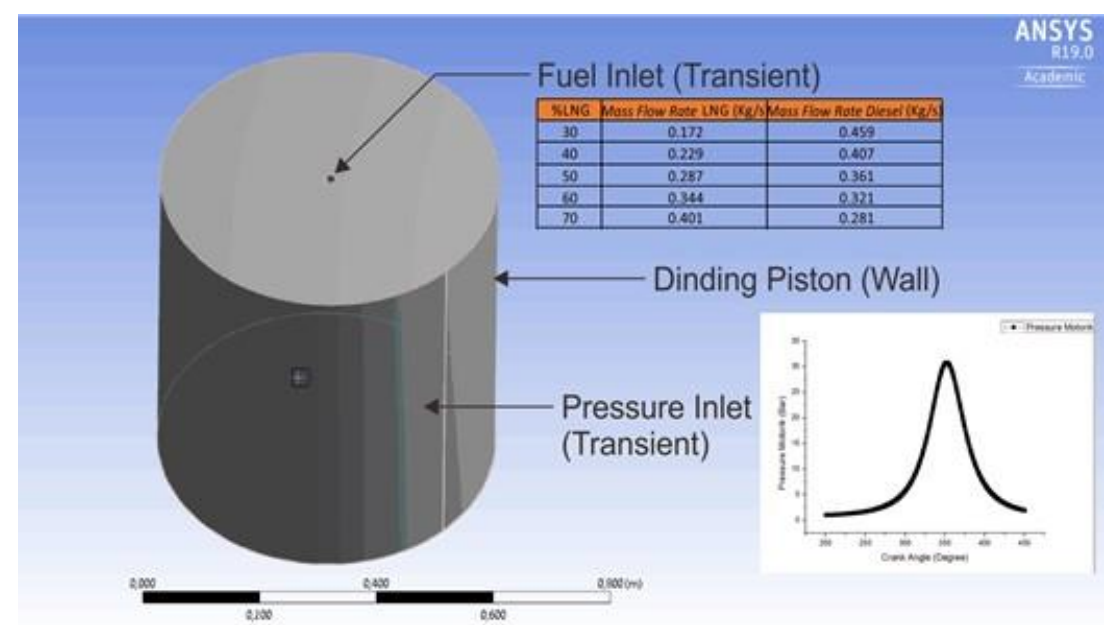

Fig. 4. Set up of boundary condition

\subsection{Validation Result}

In order to validate the simulation results, the cylinder pressure obtained from the previous study was compared with the current results shown in Figure 5. The previous study has been carried out an investigation of the performance diesel dual-fuel by experiment and simulation [29]. The simulation performed using AVL FIRE which is the leading computational fluid dynamics simulation package for the Internal Combustion Engine, the result shown a good agreement with experimental results.

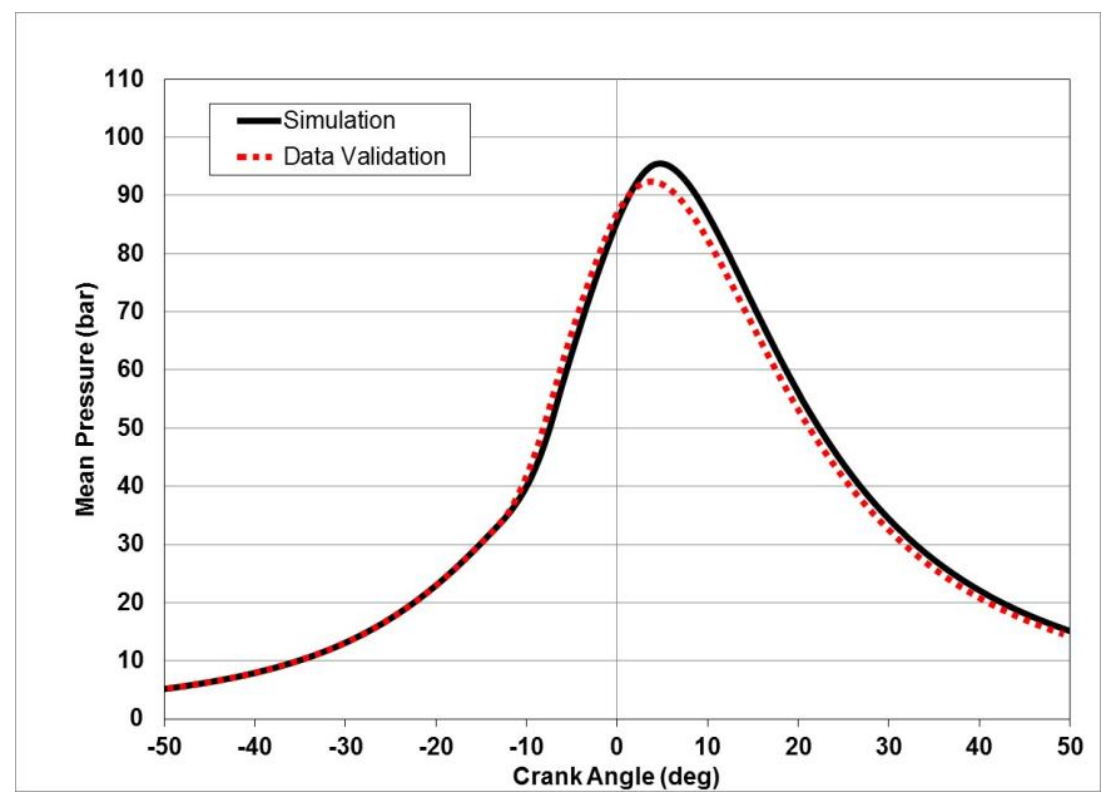

Fig. 5. Comparison of cylinder pressure between the simulation result and validation data 


\section{Results and Discussion}

Measuring the performance value of dual fuel diesel engines in this study was obtained by calculating using the formula that has been used in the research chapters. This study was conducted based on data provided by the company. The parameters used are to determine the value at the $30 \%$, $40 \%, 50 \%, 60 \%$, and $70 \%$ used LNG-diesel mass fraction used by the dual-fuel engine of the 3200 DWT passenger vessel. The mass flow rate value is calculated and obtained based on data provided by the MTRI. From the data provided, the use of fuel based on the duration of the trip in one voyage then processed to get fuel consumption every second.

At Figure 6, the angle of the crank angle starts at $270^{\circ}$ to $450^{\circ}$. At an angle of $270^{\circ}$ is the condition where the cylinder is undergoing a compression step that is the reduction of the volume of the cylinder chamber to increase the pressure. The compression step ends at a $360^{\circ}$ angle because, at this angle, the cylinder is at the top dead center and is unlikely to re-compress. After passing the 360 - angle, the cylinder moves toward the bottom dead center to perform the working step until the angle reaches $540^{\circ}$. At the angle of the crank angle is $270^{\circ}$, the pressure on the cylinder begins to rise, but the rise of the pressure has a sloping trend. The increase continues to occur at an angle of $350^{\circ}$. After passing through the $350^{\circ}$ angle, the increase in pressure occurs significantly. This is indicated if the angle crank angle is going on the process of combustion. The pressure rise has a peak value at a $360^{\circ}$ angle. After passing the $360^{\circ}$ angle, the cylinder pressure decreases this due to volume expansion resulting in the pressure inside the cylinder decreasing.

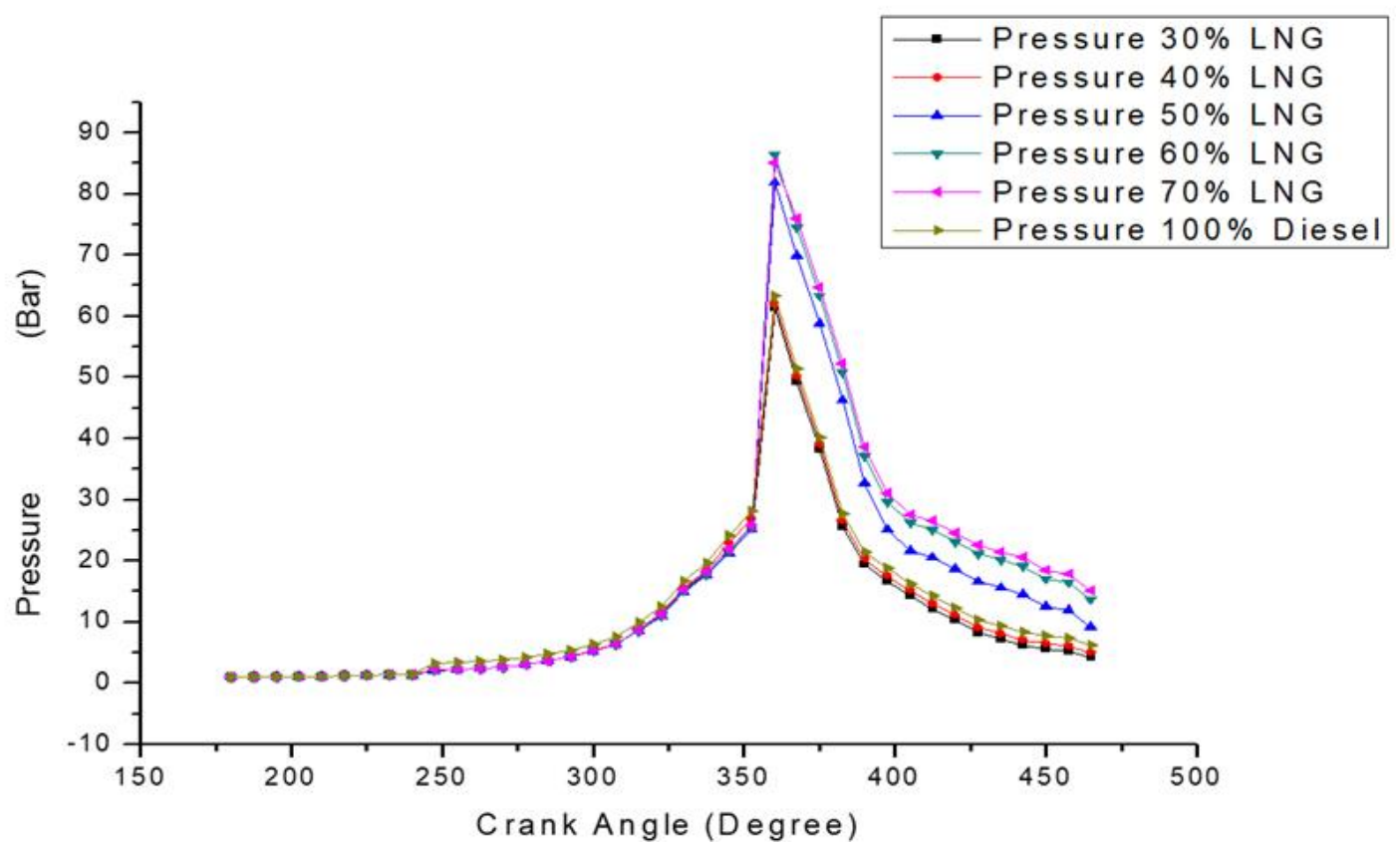

Fig. 6. Cylinder pressure on the variation of gas mixture

The pressure height values in each LNG-diesel variation vary. In a 30\% LNG mixture, the maximum pressure generated at the combustion is $60,000 \mathrm{~Pa}$, but with the addition of flow rate from LNG, the pressure on the cylinder increases up to $80,000 \mathrm{~Pa}$ in the $60 \%$ LNG mixture. Increased pressure on the cylinder in line with the addition of mass flow rate in LNG is due to the value of lower heating value in LNG greater than diesel which will result in LNG energy will be greater than diesel-generated energy. 
The value of the mean effective pressure obtained on each percentage of LNG-Diesel fuel consumption has different values. The value of the mean effective pressure is only influenced by the work net generated by each percentage of fuel due to the same combustion chamber at each percentage of the fuel. The work net value obtained by each percentage of fuel has a relation to pressure in Figure 7. Because, the greater the pressure reached in a combustion cycle, the greater the value of the work that can be generated. The percentage of 30\% of LNG-diesel fuel has a mean effective pressure value of $515.88 \mathrm{kPa}$. Then, as the LNG flow rate added into the combustion chamber, the mean effective pressure value increases until the $60 \%$ percentage of fuel have a mean effective pressure of $1730.63 \mathrm{kPa}$.

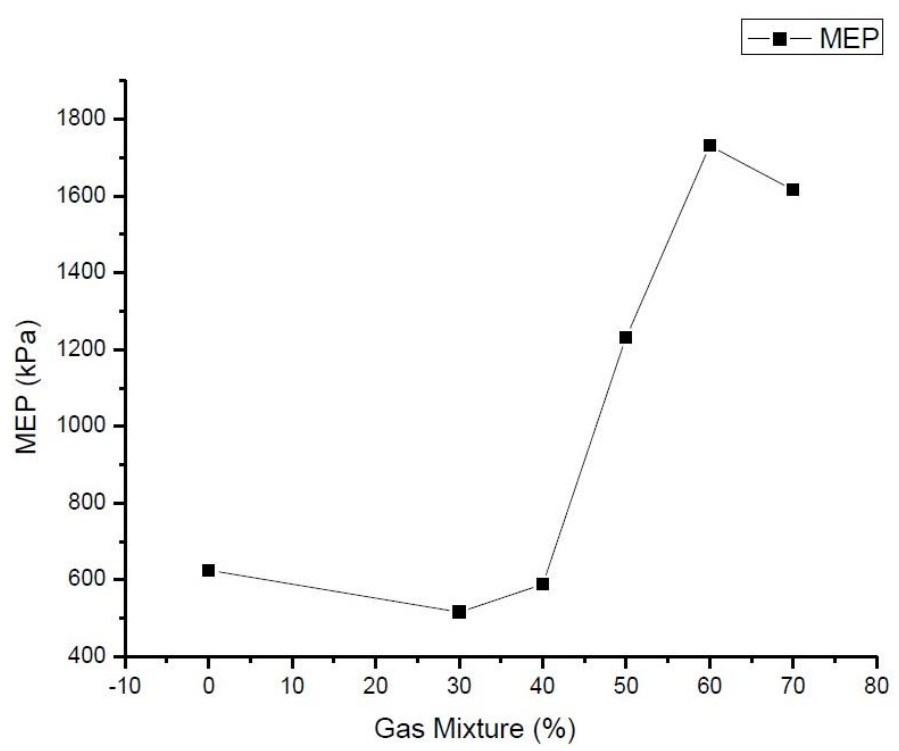

Fig. 7. Mean Effective Pressure on the dual fuel condition

The relationship between the graph of the mean effective pressure also has an effect on the torque obtained. Percentage of fuel use condition with percentage $60 \%$ has a torque of $23424.15 \mathrm{NM}$ and at $30 \%$ usage condition having torque of 6982.52 NM. Can be seen from the trend of the graph when the addition of LNG flow mass into combustion chamber, at a certain point, can add torque to the engine the big difference in torque obtained in the percentage of $30 \%$ LNG usage and $60 \%$ usage, the torque increases up to three times in Figure 8.

Another relationship that affects the value of mean effective pressure is between the amount of engine power obtained. Viewed from Figure 9, the addition of LNG flow mass also affects the power performance of the engine. At 30\% LNG percentage, engine power obtained based on mean effective pressure is $295.98 \mathrm{~kW}$. And at $60 \%$ the LNG percentage has the power of $992.94 \mathrm{~kW}$. From the graphic form obtained can be seen if the addition of LNG into the combustion chamber can increase the value of power in the combustion engine. The power difference between the usage percentage of $30 \%$ and $60 \%$ triples. 


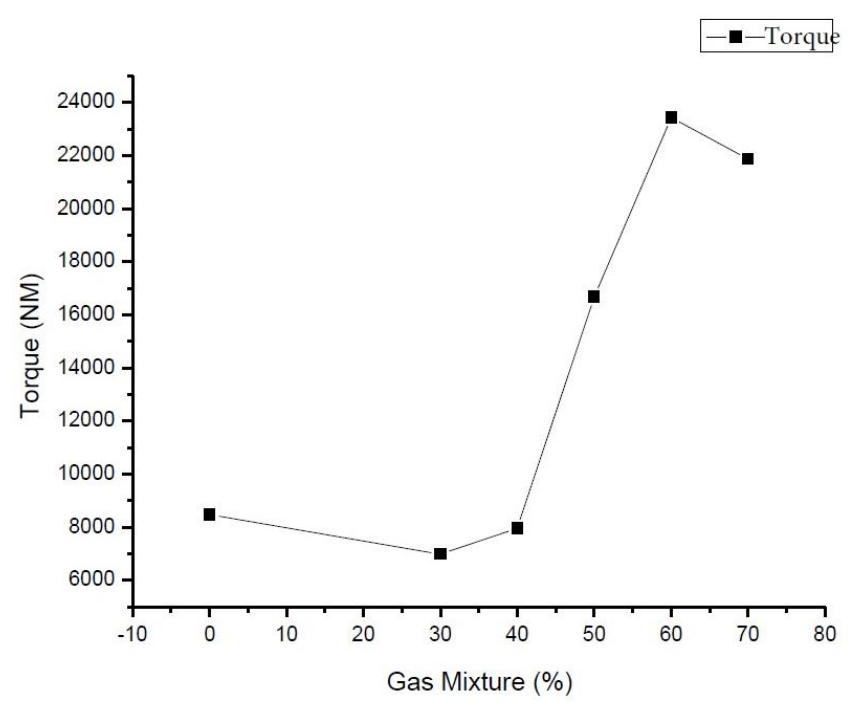

Fig. 8. Torque on the dual fuel condition

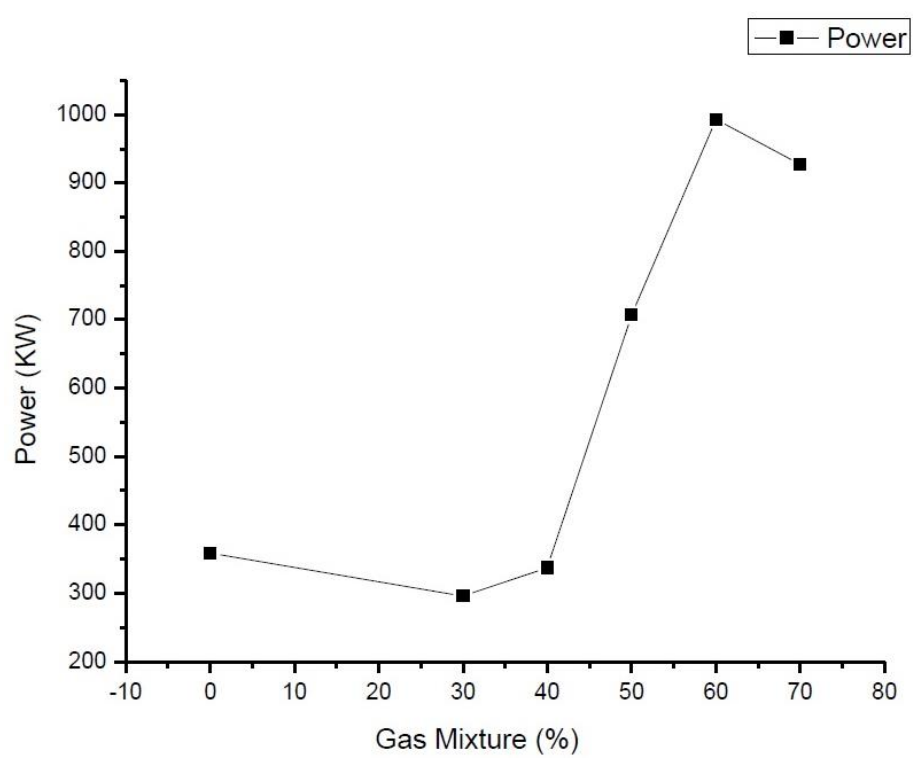

Fig. 9. Power on the dual fuel condition

From the three graphs obtained, the addition of LNG into the combustion chamber improves the performance of torque, power and also mean effective pressure on the combustion engine. The LNGDiesel mass flow rate is calculated based on the data of fuel consumption given by the company and processed and then got the value, the mass flow rate of the LNG-Diesel mixture is calculated based on the mass fraction on the mixture of both fuels and processed to obtain the specific fuel consumption graph for the percentage change of the LNG-Diesel mixture.

Lower heat value determined by the property of the LNG fuel type and also the diesel. As shown in Figure 10, the specific fuel value for each percentage of fuel has a different value from the range of $0.74 \mathrm{~kg} /$ to $2.21 \mathrm{~kg} / \mathrm{kW}$. At the fuel consumption percentage of $30 \%$, the specific fuel consumption value is highest than the other fuel consumption percentage of $2.21 \mathrm{~kg} / \mathrm{kW}$. With the added use of LNG into the combustion chamber, the specificity fuel consumption value of the engine decreases to the smallest specificity fuel consumption value in the $60 \%$ LNG-diesel mixture of $0.74 \mathrm{~kg} / \mathrm{kW}$. In other words, the $60 \%$ LNG-diesel percentage mix is the most efficient mixture because it can get the least amount of fuel mass per second power even though this percentage has the greatest power value than any other LNG-diesel percentage. 


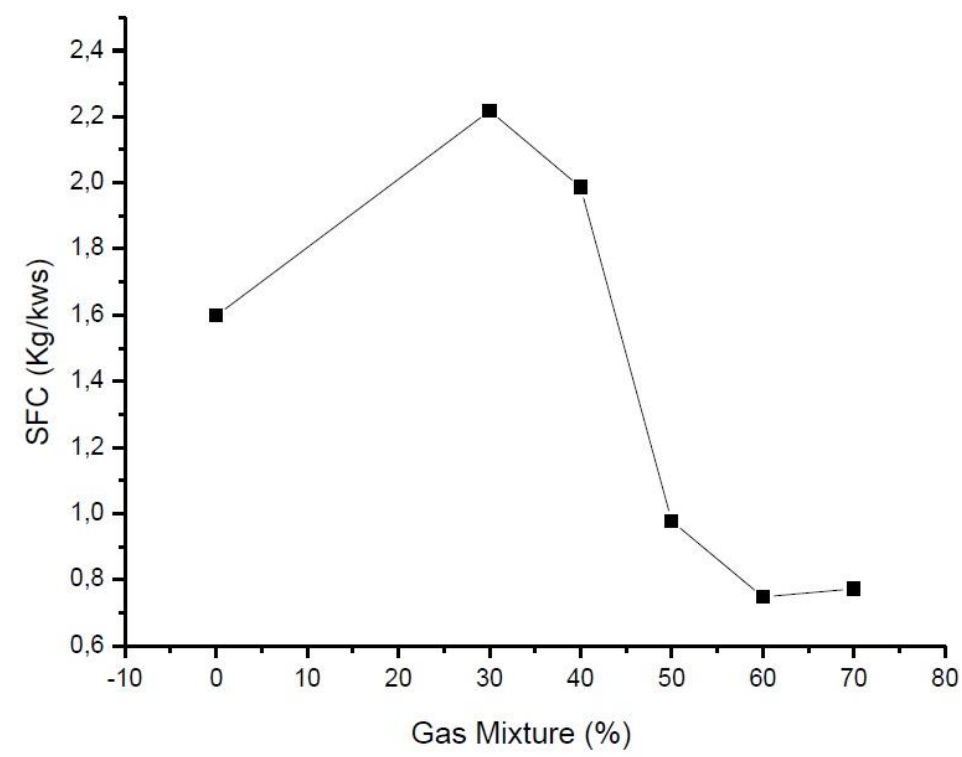

Fig. 10. Specific Fuel Consumption on the dual fuel condition

The value of thermal efficiency is calculated on each percentage of LNG-diesel fuel to know how efficiently the usage is based on the amount of work performed on the given heat. In Figure 11, the efficiency gained is between 10 and 31 percent. This efficiency value is calculated from the power obtained by the mean effective pressure. The smallest thermal efficiency value is obtained by the percentage of LNG-diesel fuel consumption in the $30 \%$ mixture. Then, the greatest thermal efficiency is obtained by a $60 \%$ mixture. It can be seen if the mixture of $30 \%$ and $40 \%$ has not big enough difference, but after the fuel consumption rate is increased, thermal efficiency increases and decreases at the percentage of $70 \%$ LNG-diesel usage. From the results obtained, the work net affects the magnitude of MEP, power, torque, SFC and nTh where the increase in work net value is directly proportional to MEP, power, torque, and thermal efficiency. However, it is inversely related to the value of SFC.

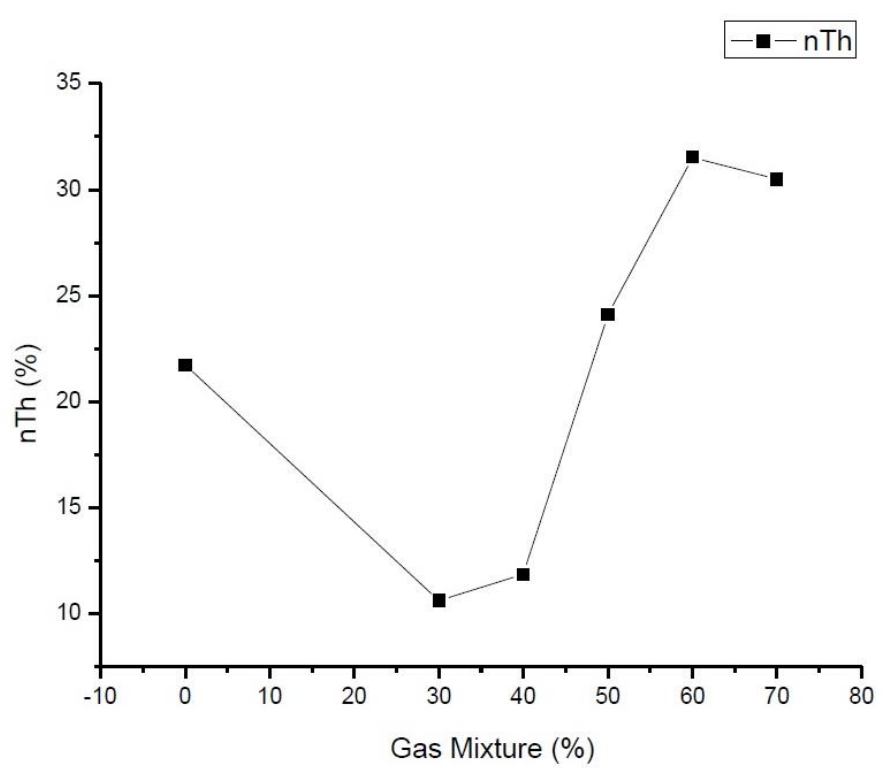

Fig. 11. Thermal efficiency on Dual Fuel Condition 


\section{Conclusion}

The analysis of this study indicates that the characteristics of each percentage of LNG and diesel usage can be parameters in determining the performance of dual-fuel diesel engines. The analysis determined based on the empirical equations of literature and simulation using the software. The conclusions obtained based on simulation and analysis of this research as follows

i. The given variation value determines $30 \%, 40 \%, 50 \%, 60 \%, 70 \%$ influence different performance changes in each variation because LNG and diesel have different fuel properties.

ii. From the performance results by each variation of fuel consumption, the value of power, torque, and also the mean effective pressure is influenced by the maximum pressure that can be achieved by the LNG-diesel mixture at the time of the compression phase to the working step. In this case, the fuel that has more LNG percentage then has better performance than the fuel that has fewer LNG percentage

iii. Based on the SFC graph and thermal efficiency, the addition of LNG content to this mixture results in reduced SFC values as well as increased thermal efficiency

iv. The addition of LNG content to the LNG-diesel mixture largely improves engine performance because the lower heating value of LNG is greater than the value of diesel's lower heating value.

\section{Acknowledgement}

The authors are thanks to the Directorate of Research and Community Engagement Universitas Indonesia (DPRM-UI) with grant PITTA B No: NKB-0761 / UN2.R3.1 / HKP.05.00 / 2019. Authors also grateful to Ministry Transportation of Republic Indonesia for supporting the ship data and also the Department of Mechanical Engineering Universitas Indonesia for supporting the software license.

\section{References}

[1] Lin, Cherng-Yuan, and Kuo-Hua Wang. "Diesel engine performance and emission characteristics using three-phase emulsions as fuel." Fuel 83, no. 4-5 (2004): 537-545.

https://doi.org/10.1016/i.fuel.2003.08.012

[2] Carlton, J., Aldwinkle, J., \& Anderson, J. (2013). Future ship powering options: exploring alternative methods of ship propulsion. London: Royal Academy of Engineering.

[3] Sea Transportation Statistic 2017, Jakarta, 2017.

[4] El-Gohary, M. Morsy. "The future of natural gas as a fuel in marine gas turbine for LNG carriers." Proceedings of the Institution of Mechanical Engineers, Part M: Journal of Engineering for the Maritime Environment 226, no. 4 (2012): 371-377.

https://doi.org/10.1177/1475090212441444

[5] K. Ito. Asia/World Energy Outlook 2016, 2016.

[6] PT. Pelni. Transformation Towards Higher Growth, 2016.

[7] Herdzik, Jerzy. "LNG as a marine fuel-possibilities and problem." Journal of KONES 18 (2011): 169-176.

[8] Burel, Fabio, Rodolfo Taccani, and Nicola Zuliani. "Improving sustainability of maritime transport through utilization of Liquefied Natural Gas (LNG) for propulsion." Energy 57 (2013): 412-420.

https://doi.org/10.1016/i.energy.2013.05.002

[9] Cheenkachorn, Kraipat, Chedthawut Poompipatpong, and Choi Gyeung Ho. "Performance and emissions of a heavy-duty diesel engine fuelled with diesel and LNG (liquid natural gas)." Energy 53 (2013): 52-57. https://doi.org/10.1016/j.energy.2013.02.027

[10] Alla, GH Abd, H. A. Soliman, O. A. Badr, and MF Abd Rabbo. "Effect of injection timing on the performance of a dual fuel engine." Energy conversion and Management 43, no. 2 (2002): 269-277. https://doi.org/10.1016/S0196-8904(00)00168-0

[11] AEsoy, Vilmar, Per Magne Einang, Dag Stenersen, Erik Hennie, and Ingebrigt Valberg. LNG-fuelled engines and fuel systems for medium-speed engines in maritime applications. No. 2011-01-1998. SAE Technical Paper, 2011. https://doi.org/10.4271/2011-01-1998 
[12] Raj, R. Thundil Karuppa, and Renganathan Manimaran. "Effect of swirl in a constant speed DI diesel engine using Computational Fluid Dynamics." CFD Letters 4, no. 4 (2012): 214-224.

[13] Isa, N. M., RA Mohamad Rushdi, A. Sadikin, S. M. Basharie, M. Universiti, and T. Hussein. "Investigation of the Fluid Motion with Various Clearances in Biodiesel Reactor by Using CFD." Journal of Advanced Research Design 10, no. 1 (2015): 1-8.

[14] Ruzi, N. A., W. J. Yahya, H. Abd, and N. A. Mazlan. "Emission of Diesel Engine Running on Emulsion Fuel Made from Low Grade Diesel Fuel." Journal of Advanced Research in Materials Science 15, no. 1 (2015): 1-8.

[15] Kassa, Mateos, and Carrie Hall. "Dual-fuel combustion." In The Future of Internal Combustion Engines. IntechOpen, 2018.

https://doi.org/10.5772/intechopen.80570

[16] Kumaraswamy, A., and B. Durga Prasad. "Performance analysis of a dual fuel engine using LPG and diesel with EGR system." Procedia engineering 38 (2012): 2784-2792. https://doi.org/10.1016/j.proeng.2012.06.326

[17] Ashok, B., S. Denis Ashok, and C. Ramesh Kumar. "LPG diesel dual fuel engine-A critical review." Alexandria Engineering Journal 54, no. 2 (2015): 105-126. https://doi.org/10.1016/j.aej.2015.03.002

[18] Wärtsilä, Dual- fuel engines from wärtsilä, (2019).

[19] Pamitran, Agus Sunjarianto, Muhammad Arif Budiyanto, and R. Maynardi. "Analysis of ISO-Tank Wall Physical Exergy Characteristic: Case Study of LNG Boil-off Rate from Retrofitted Dual Fuel Engine Conversion." Evergreen 6, no. 2 (2019): 134-142. https://doi.org/10.5109/2321007

[20] Weaver, Christopher S., and Sean H. Turner. Dual fuel natural gas/diesel engines: technology, performance, and emissions. No. 940548. SAE Technical Paper, 1994.

https://doi.org/10.4271/940548

[21] Yanmar. Dual-Fuel Marine Engine (Highly Reliable Environmentally Friendly Engine), 2019.

[22] Y. Nilsson. Cylinder volume function for SVC engines, 2019.

[23] Tindal, M. J., and O. A. Uyehara. "Diesel engines." In Internal Combustion Engines, pp. 101-155. Academic Press, 1988.

https://doi.org/10.1016/B978-0-12-059790-1.50009-2

[24] Heywood, John B. "Combustion engine fundamentals." 1̣ Edição. Estados Unidos (1988).

[25] Fluent, Ansys. "Fluent 12. Theory guide." (2017).

[26] König, Carola S. "Art and color in the context of CFD: Towards a better engineering design." (2011).

[27] Zainal, S., C. Tan, C. J. Sian, and T. J. Siang. "ANSYS simulation for Ag/HEG hybrid nanofluid in turbulent circular pipe." Journal of Advanced Research in Applied Mechanics 23, no. 1 (2016): 20-35.

[28] Stolarski, Tadeusz, Yuji Nakasone, and Shigeka Yoshimoto. Engineering analysis with ANSYS software. ButterworthHeinemann, 2018.

[29] Budiyanto, Arif, Bambang Sugiarto, and Bagus Anang. "Multidimensional CFD simulation of a diesel engine combustion: A comparison of combustion models." In Proceedings of the FISITA 2012 world automotive congress, pp. 879-893. Springer, Berlin, Heidelberg, 2013. https://doi.org/10.1007/978-3-642-33750-5 5

[30] Matsushima, Tatsuhito. "An automatic mesh generator based CFD system to be used as a design tool." SAE transactions (2001): 90-98. https://doi.org/10.4271/2001-01-0037

[31] Bathe, Klaus-Jürgen, and Hou Zhang. "A mesh adaptivity procedure for CFD and fluid-structure interactions." Computers \& Structures 87, no. 11-12 (2009): 604-617.

https://doi.org/10.1016/j.compstruc.2009.01.017 